\title{
Hinchingbrooke revisited
}

In August last year our editorial ${ }^{1}$ was prompted by the award of the 'Top Quality of Care Award' to Hinchingbrooke Hospital, the first English hospital run by a private company, Circle, delivering services via an operating franchise awarded by the NHS. The basis of the award was performance in a panel of 12 medical indicators (hospital stay, mortality rates, cancer waiting times etc) $;^{2}$ although some cynicism was expressed about the award ('the private health industry patting itself on the back'), ${ }^{3}$ it seemed nonetheless a truly remarkable achievement for a hospital described a couple of years before as a clinical and financial basket case. ${ }^{4}$ One caveat of our editorial was that the Care Quality Commission (CQC) had not then visited.

A great deal of water has passed rapidly under the bridge since then. Circle withdrew from the contract in January 2015, citing a reduction in funding, a surge in emergency demand, and disagreements with the conclusions of the eventual CQC visit. Circle's report of the reduction in funding has been challenged by the main commissioner, ${ }^{5}$ and a surge in emergency demand is scarcely unique to Cambridgeshire and Peterborough. Strikingly the announcement of the withdrawal came on the same day as the publication of the CQC report classifying the hospital's services as being overall 'inadequate'. ${ }^{6}$

Many messages emerge from these events. They are seen by some as potentially ending the involvement of private sector companies in providing acute hospital services, as Circle had their fingers badly burned. Other conclusions espoused are that this particular franchising system, applied to a failing hospital, was bound to fail because of the burden of legacy debt. One thing certainly emphasised by the saga is that while private companies can wash their hands of 'too difficult' issues, the NHS cannot: the acute medical services for the population around Hinchingbrooke were the responsibility of the NHS, and still are. All these aspects are currently fuelling the debate on the future of the nation's health services, undergoing various interpretations by political candidates and political commentators.

There are however other messages emerging from the events at Hinchingbrooke, emphasised by the opening sections of the CQC report. As noted above, on many previously published parameters this was a good hospital or at least an average hospital. The CQC's 'intelligent monitoring system' had placed it in the lowest risk category. ${ }^{6}$ Mortality indices showed no evidence of risk. The Trust was average in all sections of the
Inpatient Survey 2013. Bed occupancy was comfortably below the England average and indeed less than the $85 \%$ at which it is suggested patient care becomes affected. Length of stay, fourhour A\&E target waiting times and referral to treatment times were consistently good. Yet the overall rating was inadequate, with this rating being applied at the divisional level to both urgent and emergency services, and to medical care. In total, 33 specific directives to improve poor practice appear in the summary of findings in the report.

One immediate question that emerges from the foregoing is: Are the regularly monitored published standards referred to above fit for purpose? The A\&E department which acquitted itself well on the four-hour waiting time standard was deemed on inspection to be inadequate in respect of safety, including inadequate paediatric care, and minimal incident reporting. The medical services that had ticked the appropriate boxes for length of stay and bed occupancy were, on inspection, found to provide poor emotional and physical care, lacking respect and exhibiting poor standards on hygiene and pressure ulcer prevention. If services judged as inadequate perform well against a set of standards, surely those standards need modification and refinement?

On the other hand, the CQC's methodology in reaching its conclusions will be questioned. For example, as the Trust's Medical Advisory Committee commented, ${ }^{7}$ and indeed the CQC report itself acknowledges, concerning the management of emergency patients with respect and dignity: there is a gross discrepancy between the good results for Hinchingbrooke's A\&E department in CQC's own national patient survey on caring for patients, and the small but overwhelmingly negative sample of reports they received during the inspection.

Another area where discordant views emerge concerns the role of clinicians and frontline staff in management. Its management model has been held up as unique in that it is led by clinicians. ${ }^{7}$ One particular area flagged by the press when considering the hospital last year, and put forward as a major reason for the apparently stellar performance, was the positive role of new techniques of staff involvement, including Toyotatype innovations such as 'Stop the Line' to empower staff of all grades. ${ }^{8}$ Yet the CQC maintains that, in fact, staff were neither engaged nor empowered to take responsibility to do just that.

While many healthcare workers, wedded to the traditional concept of the NHS, may welcome the debacle of the Hinchingbrooke franchise experiment, there are of course no

$\begin{array}{ll}\text { Members of the editorial board } \\ \text { Professor Humphrey Hodgson } & \text { Dr Cordelia Coltart } \\ \text { Editor } & \text { International editor } \\ \text { Dr Paul Grant } & \text { Cono Ariti } \\ \text { Editorial registrar } & \text { Statistical editor }\end{array}$

Dr Na'eem Ahmed Paul Belcher

Dr Rodger Charlton

Dr Tahseen Chowdhury

Nick Cork

Dr Kate Evans

Professor Brian Hurwitz
Dr Angela King Professor Martin McKee Dr Mehool Patel Dr Roby Rakhit Dr Ian Starke Dr Kevin Stewart Professor Cameron Swift 
winners in the situation. Certainly not the private sector, whose aspirations will be altered in the short term, nor the patients, as in at least some departments their care was manifestly inadequate. And certaining not the medical and nursing staff who now have the unenviable task of rebuilding confidence against the background of this report; all clinicians will surely empathise with them at this juncture.

\section{References}

1 Hodgson H. Happenings at Hinchingbrooke. Clin Med 2014;14:333.

2 Circle. Hinchingbrooke Hospital named "best Trust in England for quality of care". Circle, 15 May 2014. Available online at www. circlepartnership.co.uk/about-circle/media/hinchingbrookehospital-named-"best-trust-in-england-for-quality-of-care" [Accessed 27 January 2015].

3 Cambridge News. How quality of care at Hinchingbrooke Hospital has been declared best in England - after it was placed in hands of private firm Circle. Cambridge News, 14 May 2014. Available online at www.cambridge-news.co.uk/quality-care-Hinchingbrooke-
Hospital-declared-best-England-placed-hands-private-firm-Circle/ story-22369612-detail/story.html [Accessed 27 January 2015].

4 Democracy Live. Minister: Hinchingbrooke hospital a 'basket case' BBC News, 10 November 2011. http://news.bbc.co.uk/democracylive/ hi/house_of_lords/newsid_9636000/9636182.stm [Accessed 27 January 2015].

5 Limb M. Circle's NHS failure: where now for the private sector? BMJ 2015;350:h325.

6 Care Quality Commission. Hinchingbrooke Hospital Quality report. Newcastle upon Tyne: Care Quality Commission, 9 January 2015. Available online at www.cqc.org.uk/sites/default/files/new_reports/ AAAA2986.pdf [Accessed 27 January 2015].

7 Hamilton S. Hinchingbrooke Hospital's reply to "inadequate" rating. BMJ 2015;350:h293.

8 Moore C. Set doctors and nurses free to use their common sense - as Hinchingbrooke Hospital does. The Telegraph, 11 October 2013. Available online at www.telegraph.co.uk/health/heal-our-hospitals/ 10372902/Set-doctors-and-nurses-free-to-use-their-common-sense-asHinchingbrooke-Hospital-does.html [Accessed 27 January 2015].

Humphrey Hodgson

\section{4" Royal College Q. of Physicians}

\section{$\uparrow$}
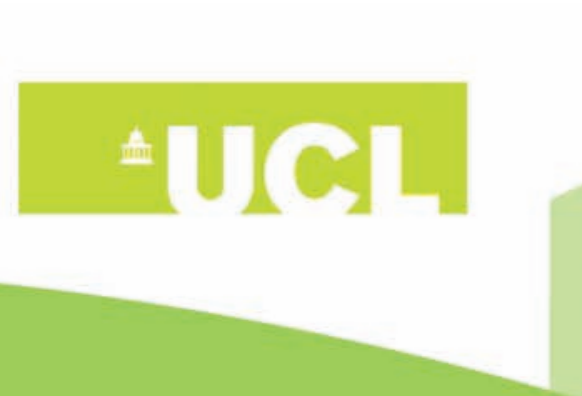

\section{'Interesting, intellectually stimulating. Excellent instructors who are able to bring subjects to life by delivering interactive sessions.' Past MSc student}

\section{Applications now open MSc in Medical Education 2015/16}

Delivered by experienced teachers and senior clinical medical education leads and consultants, this part-time, modular programme is designed for doctors wishing to develop in their role as educators. It is designed to equip doctors to use appropriate teaching strategies and educational theories to enhance the way they support learning. Applications close 1 May 2015 